\title{
"SÓLO RECUERDO LA EMOCIÓN DE LAS COSAS": ECOS DE LA POÉTICA DE WILLIAM WORDSWORTH EN ANTONIO MACHADO
}

\author{
Cristina Flores Moreno, Universidad de La Rioja ${ }^{1}$ \\ Email: cristina.flores@unirioja.es
}

Poetry is the spontaneous overflow of powerful feelings; it takes its origin from emotion recollected in tranquillity.

William Wordsworth

Sólo recuerdo la emoción de las cosas,

Y se me olvida todo lo demás;

Muchas son las lagunas de mi memoria.

Antonio Machado

Resumen: Este trabajo tiene como objetivo identificar los ecos de la teoría de William Wordsworth según la cual la poesía tiene origen en el recuerdo tranquilo de emociones pasadas en la poética de Antonio Machado. Para ello será primero necesario el estudio de las posibles vías de transmisión de dicha idea en el contexto intelectual del poeta español. Finalmente, el análisis de algunas de las obras de Machado nos permitirá constatar la influencia de Wordsworth en su visión de la creación poética.

Palabras clave: William Wordsworth, Antonio Machado, Romanticismo, recepción, poética, poesía.

Title in English: "I only remember emotions": Echoes of William Wordsworth's Poetics in Antonio Machado

\begin{abstract}
The aim of this article is to identify and analyse the echoes of William Wordsworth's concept of poetry as originating from emotion recollected in tranquillity present in Antonio Machado's poetics and poetry. First, it will be necessary to dive into the circulation and transmission of Wordsworth's poetics in Machado's intellectual context in order to discover how it could have found its way into his poetics and verses. Finally, some examples from Machado's works will help us trace the echoes of the British romantic poet's theory.

Key words: William Wordsworth, Antonio Machado, Romanticism, reception, poetics, poetry.
\end{abstract}




\section{TINTES ROMÁNTICOS EN ANTONIO MACHADO: WILLIAM WORDSWORTH}

Es algo sabido que la poesía de Antonio Machado, pilar esencial de la renovación poética que eclosionó a comienzos del siglo XX en las letras españolas, presenta tintes románticos. El poso romántico existente en el pensamiento del poeta español ha sido defendido por un buen número de autores que han intentado contestar a la pregunta que el propio Machado dejaba sin respuesta en su "Retrato” poético: “Soy clásico o romántico? No sé". 2 Ángel González (1999) muestra alguno de los aspectos que, a su parecer, el poeta español heredó de la tradición romántica inglesa y alemana, y afirma además que se ha insistido relativamente poco en las relaciones, claras e importantes, que existen entre la poesía de Machado y el romanticismo. En esa misma línea, Gutierrez-Girardot defiende que "Machado es en España quizá el más consciente romántico de su historia literaria" (1969: 22). Igualmente, Ana Lucas describe a Machado como "uno de los últimos poetas románticos" (1989: 37) y a su obra como "la de un romántico" (28). Es por todo ello que la obra de Antonio Machado resulta terreno fértil para el estudio de la recepción en España de la poética romántica. En el presente trabajo nos ocuparemos en concreto del estudio de la pervivencia en los versos de Machado de la personal visión de William Wordsworth sobre la naturaleza del acto poético.

Antes que yo otros autores han establecido ciertas conexiones entre ambos poetas. Dos son las referencias ineludibles al entablar un nuevo estudio comparativo: por un lado, el artículo de Sally Harvey (1990) sobre la presencia del inglés en la poesía de Machado y, por otro, el capítulo dedicado a este último en el magnífico ensayo de Jordi Doce (2005) sobre la presencia del romanticismo inglés en la poesía española contemporánea. En el primero, la autora enumera las características románticas que encuentra en la obra de Antonio Machado y que ya estaban presentes en la poesía del inglés:

(...) la preocupación por la sinceridad; la expresión espontánea de las emociones; la intensa reacción, hondamente espiritual, ante la Naturaleza, y las reflexiones inspiradas por ella; el sentido de la alienación del artista y su insatisfacción con el estado del mundo; la inquietud moral y filosófica; la nostalgia y la insistencia en los tiempos más felices del pasado - elementos todos presentes tanto en la obra de Machado como en la de Wordsworth. (Harvey 1990: 45)

No obstante, los rasgos descriptivos de la poesía de Machado señalados por Harvey son lugares comunes del romanticismo inglés en general y, en consecuencia, bien podrían ser la base de comparación con cualquiera de los autores pertenecientes a ese movimiento. En el desarrollo de su argumentación, esta autora se centra brevemente en algunos temas que considera propios de Wordsworth. En primer lugar, analiza la defensa realizada por ambos poetas del lenguaje común como material óptimo para la creación poética. Sin embargo, es necesario recordar que esta propuesta de Wordsworth a favor del lenguaje común pertenece originariamente al prefacio de la primera edición de Lyrical Ballads,

\footnotetext{
2 Todas las citas de la obra poética de Antonio Machado incluidas en este trabajo pertenecen a la siguiente edición: Machado, Antonio. 1991. Poesías Completas. Madrid: Espasa Calpe. A partir de ahora serán señaladas entre paréntesis como $P C$ seguido de número de página y verso. Esta cita $(P C 150,21)$.
} 
cuya autoría es compartida con Samuel Taylor Coleridge. Jordi Doce, así lo entiende y comenta al respecto: "Machado conecta con los autores de Baladas Líricas gracias a este énfasis en un regreso a la tradición oral de las canciones y las baladas" (2005: 172). Además, Harvey subraya especialmente la decepción y tristeza sufrida tanto por Machado como por Wordsworth como resultado de la situación política y social de sus respectivos momentos. Este profundo descontento mueve a Machado en la misma dirección que dos siglos antes tomara Wordsworth: ambos emprenden una huída, teñida de nostalgia, hacia la naturaleza y el idealismo.

Harvey nota cuan semejantes son ambos poetas en su profundo amor por la naturaleza con la que establecen una relación espiritual y mística, así como el papel relevante que ésta adquiere en el pensamiento poético de ambos. Por su parte, Jordi Doce dedica unas páginas a elaborar un estudio comparativo de la poesía de Campos de Castilla y los poemas que Coleridge y Wordsworth dedican a ciertos paisajes que se tornan reflejos del alma a través de sus versos (Doce 2005: 188-205). Este autor hace especial hincapié en las semejanzas existentes entre la poesía de Machado y los llamados "poemas conversacionales" de Coleridge: "en los que el reconocimiento del objeto enlaza con una verdadera obsesión por la perspectiva extraordinaria" (198).

El presente trabajo parte de estas consideraciones generales para centrarse en un aspecto muy concreto de la poética de William Wordsworth, una idea central en su visión del acto creativo que hasta el momento no ha sido analizada en la obra de Machado y que, sin embargo, tiene mucho que ver con esa búsqueda de una perspectiva extraordinaria. Me refiero a la bien conocida teoría esgrimida por el poeta inglés en el Prefacio a la edición de 1800 de Lyrical Ballads, según la cual la poesía surge a partir de la explosión de sentimientos producidos ante la recreación tranquila de recuerdos de emociones pasadas.

\section{CIRCULACIÓN Y TRANSMISIÓN DE IDEAS: DE WORDSWORTH A MACHADO}

Antes de analizar las obras de Machado en busca de ecos de dicha teoría es primero necesario llevar a cabo un estudio de los posibles cauces de su transmisión en el contexto intelectual del poeta español. Para ello, se considerará en primer lugar la posible lectura directa de la obra de Wordsworth por parte de Machado para, a continuación, ofrecer una visión general de las posibles vías indirectas de influencia a través de las cuales el concepto de poesía propuesto por Wordsworth pudo haber sido trasmitido al autor español.

En cuanto a la lectura directa de la poesía de Wordsworth por parte de Machado, es importante reseñar que, hasta lo que he podido comprobar, la primera traducción de una pequeña selección de poemas de Wordsworth al castellano es la realizada por Marià Manent y publicada en 1945 dentro de una antología de poesía inglesa romántica y victoriana ( $L a$ poesía inglesa: Románticos y Victorianos, Barcelona: Lauro). Por lo tanto, en ausencia de traducciones al español disponibles, sólo queda la posibilidad de que Machado leyese los versos de Wordsworth en el inglés original, o a través de alguna de las traducciones al francés existentes.

No podemos probar de manera fehaciente que Machado leyese de primera mano sus obras, aunque eso no significa necesariamente que no lo hiciera. Ian Gibson (2007: 6-8) explica que Machado sentía una poderosa atracción por el idioma inglés y que se esforzó 
mucho en su aprendizaje con el fin de poder leer a Shakespeare en su lengua original. Afirma Gibson que los borradores, apuntes, manuscritos y obra publicada prueban que llegó a tener un excelente conocimiento del inglés escrito y una gran familiaridad con la lírica británica. Más aún, sigue este autor, Machado demuestra haber sentido una clara afinidad con la poesía inglesa del siglo XIX en general, muy en particular con la de Wordsworth por su sensibilidad hacia el paisaje. Por lo tanto, es probable que el poeta español tuviese conocimiento directo de la poesía del autor británico en su idioma original. Además, debido, por un lado, a su formación y carrera académica y, por otro, a los periodos pasados en Francia, cabe también la posibilidad de que tuviese acceso a algunas de las traducciones al francés de las obras de Wordsworth. Los primeros viajes de Machado a París tuvieron lugar en 1899 y 1902, para entonces ya habían sido publicadas varias traducciones de poemas de Wordsworth. ${ }^{3}$ La primera de la que tengo constancia data de 1850, y se trata de una selección de poemas traducidos por Florent Richomme titulado Ballades et petits poèmes de William Wordsworth (Paris: Hachette). Más tarde, ya a finales de siglo, Émile Legouis, gran anglófilo francés de la época, contribuyó significativamente al conocimiento del poeta británico en Francia con la publicación en 1899 y 1900 de sendos volúmenes de traducciones de una selección de poemas y extractos de la obra de Wordsworth, así como de un estudio crítico sobre The Prelude en $1896 .^{4}$ No obstante todo lo anterior, queda claro que su lectura directa de la obra de Wordsworth es más una posibilidad que una certeza.

Lo que sí que es demostrable es que el trabajo de Wordsworth era conocido y objeto de comentarios entre los escritores e intelectuales españoles que mantenían un cierto contacto con Machado, lo que constituye una vía añadida de circulación de las ideas del poeta inglés. El ambiente intelectual de principios de siglo XX en España, del que participaba Machado, era muy propicio para la recepción de los ideales románticos. La relación existente entre el Modernismo español y el Romanticismo británico ha sido ampliamente discutida. Para un estudio profundo de esta relación nos remitimos a la influyente obra de Philip W. Silver (1996), en la que se argumenta de manera convincente que las ideas del romanticismo británico no tuvieron el suficiente eco en España hasta principios del siglo XX, siendo entonces su influencia esencial en la renovación poética promovida por los autores de la Generación del 98, con Miguel de Unamuno como su principal precursor.

El trabajo de Antonio Machado se enmarca en este contexto intelectual teñido profundamente de un idealismo heredado, en parte, del romanticismo. Cardwell (2006) expone que, contra la opinión generalizada, Machado no fue ajeno a las corrientes intelectuales de su momento, y defiende que es necesario considerarle dentro del " $(. .$. complejo de ideas, planteamientos, obsesiones y preocupaciones que componen unas perspectivas o actitudes espirituales o éticas respecto al papel del artista y el papel del arte en la sociedad en un momento de enorme crisis nacional" (67). Este contexto, Cardwell

\footnotetext{
Lo que sigue no pretende ser un estudio exhaustivo de las traducciones al francés de la obra de Wordsworth, sería necesario llevar a cabo una investigación más profunda, pero ese no es el objetivo del presente trabajo.

4 Legouis, E. 1899. Auteurs du programme. Poèmes choisis, par William Wordsworth. Paris: C. Delagrave; Legouis, E. 1900. William Wordsworth. Extraits. Paris : Belin frères; Legouis, E. 1896. La Jeunesse de William Wordsworth, 1770-1798, etude sur "Le Prèlude". G. Masson.

La publicación de la primera traducción de The Prelude vendría de la mano de Louis Cazamian, ya en 1949 (Le prélude ou La croissance de l'esprit d'un poète). Antes, en 1925, Legouis y Cazamian habían publicado Histoire de la littérature anglaise (Paris: Hachette), traducida al inglés el año siguiente.
} 
continúa, se caracterizaba por "un intenso idealismo respecto a la posibilidad de una regeneración espiritual de la nación por medio del Arte y el trabajo idealista de los poetas" (76). Se trata del idealismo presente en la Institución Libre de Enseñanza, con Giner de los Ríos a la cabeza, de la que Machado fue alumno; y el trasmitido a través de las páginas de la revista Helios, en la que también colaboró junto con, entre otros, Miguel de Unamuno y Juan Ramón Jiménez. Todos ellos, de reconocida influencia romántica, compartían la creencia del poder redentor de la obra artística. La literatura constituye para estos autores una puerta de escape hacia una realidad que se les antoja más satisfactoria que la suya propia. En este sentido, Ricardo Gullón señala que uno de los propósitos principales de este grupo de autores era, en sus palabras: "adscribirse, (...) integrarse en algo distinto de lo presente" (1971: 65). Este autor desafía la descripción convencional del Modernismo español sugiriendo que:

El artista, partiendo de la herencia romántica, se siente al margen de la sociedad y rebelde contra ella. (...) En la época modernista, la protección contra el orden burgués aparece con frecuencia en formas escapistas. El artista rechaza la indeseable realidad (la realidad social: no la natural), en que ni puede ni quiere integrarse, busca caminos para la evasión. Uno de ellos, acaso el más obvio, lo abre la nostalgia, y conduce al pasado; otro, trazado por el ensueño, lleva a la transfiguración de lo distante (en tiempo o espacio, o en ambos); lejos de la vulgaridad cotidiana. (64-5)

Un sentimiento análogo de rechazo hacia la realidad presente y consiguiente huída hacia lo vivido y sentido en el pasado es lo que, un siglo antes, movió a Wordsworth a elaborar una concepción de la poesía basada esencialmente en la contemplación de los recuerdos. Como es bien sabido, Wordsworth expuso esta visión de la poesía como sigue:

I have said that poetry is the spontaneous overflow of powerful feelings; it takes its origin from emotion recollected in tranquillity; the emotion is contemplated till by a species of reaction the tranquillity gradually disappears, and an emotion, kindred to that which was before the subject of contemplation is gradually produced and does itself actually exist in the mind. (Wordsworth y Coleridge 1998: 266, mi énfasis)

Machado no fue el primero en importar esta idea. Al menos dos autores españoles, ambos extraordinariamente influyentes en el poeta, habían recogido esta idea previamente: Gustavo Adolfo Bécquer y Miguel de Unamuno. El primero expuso en Cartas literarias a una mujer (II):

Guardo, sí, en mi cerebro, escritas como en un libro misterioso las impresiones que han dejado en él su huella al pasar; estas ligeras y ardientes hijas de la sensación duermen allí agrupadas en el fondo de mi memoria hasta el instante en que, puro, tranquilo, sereno, y revestido, por decirlo así, de un poder sobrenatural, mi espíritu las evoca, y tienden sus alas trasparentes que bullen con un zumbido extraño, y cruzan otra vez a mis ojos como en una visión luminosa y magnífica. (...)

Sólo a algunos seres les es dado el guardar, como un tesoro, la memoria viva de lo que han sentido. 
Yo creo que éstos son los poetas. Es más, creo que únicamente por esto lo son. (Bécquer 1995, II: 353$)^{5}$

No podemos obviar la devoción de Machado por la obra de Gustavo Adolfo Bécquer, el autor español romántico más cercano a las posturas estéticas defendidas en Gran Bretaña. No sería de extrañar en absoluto que Machado hubiese leído este pasaje de la obra de Bécquer. Posteriormente, Miguel de Unamuno recoge de nuevo esta teoría en su ensayo breve "Ciudad, Campo, Paisajes y Recuerdos" (1911):

¿Hay acaso placer mayor que, sentado en las largas noches de invierno junto a la leña que arde y zumba en la chimenea, soñar en un paisaje favorito? (...) lo he sentido; he sentido al retirarme al reposo y silencio del lecho después de un día de duro trabajo y de agitación ciudadana (...) Aún hay más, y es que durante el verano y en las siempre breves vacaciones de que durante el curso puedo gozar, salgo a hacer repuesto de paisaje, a almacenar en mi magín [imaginación] y en mi corazón visiones de llanura, de sierra o de marina, para irme luego de ellas nutriendo en mi retiro. (Unamuno 1966, I: 360)

Con anterioridad a la publicación de este texto, Unamuno ya se había hecho eco de esta idea en otros trabajos, como por ejemplo en el ensayo "Cantos de la noche" (1989) en el que, además, Unamuno parafrasea y comenta los primeros versos de "The Excursion". Más tarde, Unamuno trasladaría esta teoría a algunos de los poemas de Poesías, publicado en 1907, como por ejemplo en el titulado "En una ciudad extranjera" (fechado Oporto, julio 1906). Es difícil establecer aquí cual de los dos autores se encontró primero con esta idea. Es sabido que la poética romántica esgrimida por W. Wordsworth, S. T. Coleridge y W. Blake, este último en menor medida, marcaron profundamente el pensamiento de Miguel de Unamuno. Ya en 1890, mucho antes de conocer a Machado, Don Miguel había expresado enérgicamente su admiración por los versos de Coleridge y Wordsworth. Teniendo esto en cuenta, y dada su larga y profunda amistad, es razonable pensar que pudo ser Unamuno quien contagiase a Machado su enorme entusiasmo por los versos de los poetas lakistas. ${ }^{6}$ En cualquier caso, queda claro que compartieron este interés.

Se han trazado aquí algunos de los posibles caminos que pudo tomar esta concepción de la poesía de Wordsworth hasta llegar al poeta que nos ocupa. En lo que sigue trataré de mostrar como esta concepción de la poesía adquiere un papel central en la poética de Machado y encuentra reflejo en su poesía.

\section{MEMORIA, CONTEMPLACIÓN Y EMOCIÓN EN WORDSWORTH Y MACHADO}

Ya se ha señalado anteriormente que una de las características esenciales de los autores de la Generación del 98 es la búsqueda de caminos para la evasión a través de la nostalgia y el retorno al pasado. Indudablemente, Machado representa mejor que ninguno de los poetas

\footnotetext{
Para saber más sobre la influencia del romanticismo inglés, especialmente del concepto de imaginación, en este autor ver Bynum (1993).

6 Para un análisis más pormenorizado de la influencia de estos autores románticos en Unamuno ver: Perojo (2007); Flores (2010a, 2010b, 2011). Asimismo, la gran influencia de Miguel de Unamuno en Antonio Machado ha sido objeto de estudio por, entre otros, Aurora Albornoz (1967).
} 
contemporáneos ese sentimiento. Es un lugar común su profunda preocupación por el paso del tiempo y la imposibilidad de recuperarlo, lo que expresó en innumerables ocasiones en sus versos a través del símbolo del camino. No es de extrañar entonces que la memoria adquiera para Machado un valor terapéutico extraordinario ya que le permite trasladarse a otro tiempo pasado, huyendo así de la realidad presente que tanto detesta. El acto de recordar se convierte en una privilegiada vía de escape hacia los momentos felices vividos durante sus años más jóvenes. De ahí que un buen número de los poemas de Machado tengan como tema principal su infancia, lo que de nuevo nos lleva hasta Wordworth. ${ }^{7}$ Tanto Doce como Harvey, en los trabajos ya citados, se detienen brevemente a establecer la conexión existente entre la concepción romántica de la infancia defendida por Wordsworth, que resume en su dictum "the Child is the father of the Man", ${ }^{8} \mathrm{y}$ la de Antonio Machado. Pero, lo que principalmente nos interesa aquí es indagar un poco más en el concepto que Machado tiene de los recuerdos y las emociones, su interrelación, y el lugar que ocupan en el conjunto de su estética, con el fin de establecer su conexión con el poeta lakista. Dice Machado en Los complementarios:

Sólo recuerdo la emoción de las cosas,

Y se me olvida todo lo demás;

Muchas son las lagunas de mi memoria. (Machado 1988: 1166)

Es obvia la similitud del primer verso citado y las palabras de Wordsworth en el Prefacio. Ambos autores subrayan el acto de recordar emociones, sentimientos, más allá de las circunstancias concretas que los provocaron en el pasado. "Se me olvida todo lo demás”, dice Machado, porque lo demás, por sí sólo, no es material para versos. No se trata, por lo tanto, de una defensa de la memoria "mecánica", de la que S. T. Coleridge dice en su Biographia Literaria que tiene como tarea principal proveer al resto de las facultades los objetos sobre los que trabajar. ${ }^{9}$ En realidad, para Coleridge, Wordsworth y el mismo Machado el acto de rememorar es el primer paso a tomar; luego ha de ser seguido por la explosión de sentimientos que surge en la recreación de dichas emociones a través de la contemplación. El poeta aprisiona en su memoria la vivencia y retiene las emociones producidas para posteriormente ser liberadas en el mismo acto creativo. Para Wordsworth la memoria evoca y hace presente impresiones personales pasadas. Así lo explica en su conocido poema "Lines Composed a Few Miles above Tintern Abbey":

These beauteous forms,

Through a long absence, have not been to me,

As is a landscape to a blind man's eye:

But oft, in lonely rooms, and mid the din

Of towns and cities, I have owed to them,

In hours of weariness, sensations sweet,

\footnotetext{
Yndurain (1975:20) señala que en Soledades, y hasta 1908, el tema de la niñez aparece unas 20 veces.

8 Todas las citas de la obra de Wordsworth pertenecen a la siguiente edición de sus obras completas. Wordsworth, William. 1977. Poems, ed. By John O. Hayden, 2 vols. London: Penguin. A partir de ahora aparecerán señaladas como $P$ entre paréntesis, seguido del número de volumen y página. Esta cita: $(P$ I: 522$)$.

9 Así lo expone Coleridge: "supply to all other faculties their objects, to all thought the elements of its materials" (Coleridge 1983 I: 104).
} 
Felt in the blood, and felt along the heart; And passing even into my purer mind With tranquil restoration. ( $P$ I: 358$)$

Domingo Yndurain (1975: 21-2) en su estudio de los motivos más recurrentes de la poesía de Antonio Machado nota que con gran frecuencia el poeta acude al recuerdo, reproduciendo emociones pasadas, ya que es lo único disponible en el presente. Para el poeta español, al igual que lo fuese para Wordsworth, es un imperativo establecer la conexión entre las sensaciones e imágenes alojadas en la memoria y los sentimientos provocados por ellas, sólo así puede unir memoria y alma, sensaciones y emociones. En el poema número CXXV de Campos de Castilla, Machado escribe:

Tengo recuerdos de mi infancia, tengo imágenes de luz y de palmeras

(...)

mas falta el hilo que el recuerdo anuda

al corazón, el ancla en su ribera,

o estas memorias no son alma. Tienen,

en sus abigarradas vestimentas,

señal de ser despojos del recuerdo,

la carga bruta que el recuerdo lleva. (PC 214)

A través de un mecanismo de introspección, Machado elimina cualquier consideración exterior al recuerdo mental, lo que denomina en el pasaje anteriormente citado "despojos del recuerdo", "carga bruta”. Es así como la preocupación de Machado por el paso del tiempo y la imposibilidad de volver al pasado es relativamente minimizada por su confianza en el poder de la memoria. Ribbans describe la paradoja que siente el poeta:

Lo más característico del poeta, es, por un lado, una sensación de tirantez entre la introspección y la observación, "con los ojos abiertos", del mundo externo y, por otro, un constante vaivén entre la nostalgia por emociones pasadas y las tenues esperanzas de recuperarlas. (Ribbans 2006: 148)

En este pasaje, Ribbans nos da la clave para entender las razones que pudieron hacer despertar en Marchado su interés por la poética de Wordsworth. El poeta español pudo ver en la teoría esgrimida por el poeta británico la solución a esa tensión de opuestos, una idea que le permitiría disolver esa dualidad mundo externo-introspección, emociones pasadaspresente que, tal y como señala Ribbans, es central en su pensamiento. Y esa conciliación es posible porque, según Wordsworth, la observación del mundo exterior en el presente abre las puertas a un proceso de introspección que le lleva al pasado en un viaje de ida y vuelta en el que transporta al presente sentimientos previamente vividos.

Son frecuentes las ocasiones en las que el poeta español no encuentra inspiración en los elementos sensibles del presente y por ello ha de volver la mirada hacia el pasado, tal y como dice en el poema "Recuerdos" de Campos de Castilla: "En la desesperanza y en la melancolía / de tu recuerdo, Soria, mi corazón se abreva” (PC 209). Así, al igual que le ocurriese a Wordsworth en "Ode: Intimations of Immortality from Recollections of Early 
Childhood", Machado siente la vacuidad de la realidad de la que es testigo en el presente y siente la pérdida de su capacidad creativa. Wordsworth lo exponía así:

There was a time when meadow, grove, and stream,

The earth, and every common sight,

To me did seem

Apparelled in celestial light,

The glory and the freshness of a dream.

It is not now as it hath been of yore;-

Turn wheresoe'er I may,

By night or day,

The things which I have seen I now can see no more. ( $P$ I: 523-4, mi énfasis)

Igualmente, Machado también siente nostalgia por un pasado más fructífero, poéticamente hablando, al que retorna a través de la memoria para recobrar la creatividad tal y como describe en "Coplas mundanas":

Poeta ayer, hoy triste y pobre

filósofo trasnochado,

tengo en monedas de cobre

el oro de ayer cambiado.

(...)

Y hoy miro a las galerías

del recuerdo, para hacer

aleluyas de elegías

desconsoladas de ayer. (PC 148-9)

Decía el poeta lakista en la cita anterior que en el pasado los paisajes se le antojaban sueños que ha de recuperar en el presente. Algo parecido es lo que Machado expresa en el poema numero LXXXIX de Galerías en el que aboga por que los sueños sean recuperados a través de la memoria:

Y podrás conocerte recordando

del pasado soñar los turbios lienzos,

en este día triste en que caminas

con los ojos abiertos.

De toda la memoria, sólo vale

el don preclaro de evocar los sueños. (PC 145, 5-6)

Al igual que ocurriese en Wordsworth, el recuerdo, la contemplación y la ensoñación, esta última resultado de las dos primeras, aparecen con frecuencia unidos en la obra de Machado. Sirva de ejemplo el siguiente pasaje perteneciente a una "Carta abierta a don Miguel de Unamuno" publicada en 1903 en El País:

Hombre soy contemplativo y soñador (bien se echa de ver en cuanto escribo espontáneamente), que escucha los ruidos del mundo inerte, no por mera delectación del oído, sino por un deseo incorregible de lanzar el espíritu en el recuerdo de cuanto hay más allá 
de la memoria; que procura dar alas al propio sentimiento para que, rebasando el horizonte terreno, se inicie el alma en cuanto hay más allá de nuestra vana ciencia, saltándose así la noble tierra que huellan nuestras plantas. (mi énfasis)

La ensoñación es en ambos autores análoga al acto de creación poética. ${ }^{10}$ La nueva realidad adquirida tras la remembranza toma la forma de sueño, tal y como se puede ver en las primeras estrofas del poema "Renacimiento", en el que aparece también el tema de la infancia recobrada:

\author{
Galerías del alma... ¡El alma niña! \\ Su clara luz risueña; \\ y la pequeña historia, \\ y la alegría de la vida nueva... \\ ¡Ah, volver a nacer, y andar camino, \\ ya recobrada la perdida senda! \\ y volver a sentir en nuestra mano \\ aquel latido de la mano buena \\ de nuestra madre... Y caminar en sueños \\ por amor de la mano que nos lleva. (PC 145, mi énfasis)
}

El poeta español consigue por medio de la memoria eliminar las barreras entre lo inmutable y lo temporal, lo accidental y lo esencial, sueño y realidad, al más puro estilo romántico.

En el prólogo de 1917 a Soledades, Machado describe la que fuera por entonces su visión del elemento poético: "una honda palpitación del espíritu; lo que pone el alma, si es que algo pone, o lo que se dice, si es que algo dice, con voz propia, en respuesta al contacto del mundo" (PC 78). El elemento poético es, según Machado, la respuesta del alma del poeta ante los elementos externos, el mundo. Diría más tarde: "En mi composición Los cantos de los niños, escrita en el año 98, se proclama el derecho de la lírica a contar la pura emoción" (Machado 1988: 137). ${ }^{11}$ El objeto del poeta es, por lo tanto, reflejar la emoción, "honda palpitación del espíritu", que se produce al enfrentarse al mundo externo. Aunque en el prólogo Machado no lo señale, la lectura de Soledades revela que la emoción expresada en algunos de los poemas es producto de un acto consciente y deliberado de recordar. En numerosas ocasiones, la voz lírica vuelve la mirada no sólo hacía adentro sino también hacia el pasado en busca de esos universales del sentimiento. Y es que, además de haber incluido la teoría de Wordsworth en sus disquisiciones sobre la naturaleza y su experiencia del acto poético, Machado dramatiza en algunos de sus versos, al igual que antes hiciese el poeta británico, el mismo acto de recordar en tranquilidad. Sólo y en actitud contemplativa busca en los objetos que tiene delante la puerta de entrada a sus recuerdos de emociones pasadas. Así, por ejemplo, Machado vuelve la mirada hacia su infancia en los poemas numerados V, VI y VII. De hecho, el primero tiene como título "Recuerdo infantil" (PC 90) y en él el poeta traslada al presente la emoción vivida en un momento concreto perteneciente a su infancia, recuperando así el sentimiento de aburrimiento y monotonía vivido durante una

\footnotetext{
10 Wilson (1993) ha analizado en profundidad este aspecto del pensamiento de Wordsworth.
}

11 Los cantos de los niños fue publicada en 1909 en Soledades. 
tarde de invierno en el colegio. El siguiente poema de la colección parte de un incidente concreto, un paseo por un parque desierto y abandonado durante "una tarde clara, triste y soñolienta, (...) una tarde muerta", para describir su búsqueda de emociones pasadas en el hondo del alma. En el poema son continuas las referencias al acto de recordar: “¿Recuerdas hermano?”; “¿Te recuerda, hermano, / un sueño lejano mi canto presente?” (13-14); "Cuéntame mi alegre leyenda olvidada" (36). Aunque la respuesta que recibe es: "-Yo no sé leyendas de antigua alegría, /sino historias viejas de melancolía" (37-8). Su búsqueda de un sentimiento pasado alegre continúa en el siguiente poema, el número VII. En éste la voz lírica tiene como objetivo revivir el sentimiento de ilusión infantil: "y estoy solo, en el patio silencioso, / buscando una ilusión cándida y vieja (...) algún recuerdo" ( $P C$ 92, 10-11, 13). Y lo encuentra:

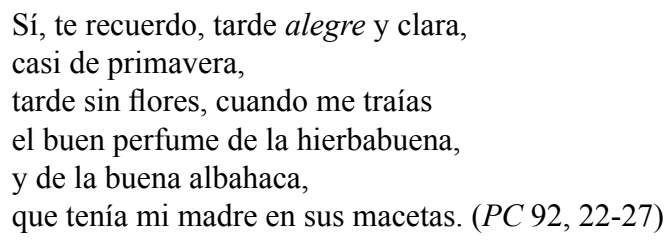

El poeta recobra la emoción vivida, traslada al presente la felicidad experimentada en el pasado y, al hacerlo, transforma su realidad inmediata.

En vista de lo anterior se puede concluir que Antonio Machado encontró en la idea de Wordsworth del poder evocador de la memoria la manera de esquivar el paso del tiempo que tanto le preocupaba, de escapar del presente que le ahogaba y recuperar así las emociones y sueños vividos en el pasado. Si bien el pensamiento poético de Machado es ampliamente conocido, no se había establecido hasta el momento su estrecha relación con la teoría originariamente esgrimida por William Wordsworth. En un contexto intelectual propicio y, probablemente, a través de su propia lectura de la obra de Wordsworth, su contacto directo con Miguel de Unamuno y su estudio atento de la obra de su admirado Gustavo Adolfo Bécquer, esta visión del acto poético se hizo camino desde el poeta lakista hasta penetrar el alma y versos de Machado.

\section{REFERENCIAS BIBLIOGRÁFICAS:}

Albornoz, Aurora de. 1967. La presencia de Miguel de Unamuno en Antonio Machado. Madrid: Gredos.

BÉCQUeR, Gustavo Adolfo. 1995. Obras Completas. 2 volúmenes. (Ed. Ricardo Navas Ruiz). Biblioteca Castro Turner

Bynum, B.B. 1993. The Romantic Imagination in the Works of Gustavo Adolfo Bécquer. Chapel Hill: University of North Carolina Press.

CARDwell, Richard A. 2006. “Antonio Machado y el idealismo finisecular" en Hoy es siempre todavía. Curso internacional sobre Antonio Machado. (Ed. Jordi Doménech) Sevilla: Renacimiento, pp. 65-86. 
Coleridge, S. T. 1983. Biographia Literaria, edited by J. Engell, and H. J. Jackson. Princeton: Princeton University Press/Bollingen

Doce, Jordi. 2005. Imán y desafio. Presencia del romanticismo inglés en la poesía española contemporánea. Barcelona: Península

Flores Moreno, Cristina. 2010a. “'Imported Seeds': The Role of William Wordsworth in Miguel de Unamuno's Poetic Renewal.” Joselyn Almeida ed. Romanticism and the Anglo-Hispanic Imaginary. New York: Rodopi. 249-272.

---.2010b. “Contemplative Unamuno: The Presence of S. T. Coleridge's 'Musings' in Miguel de Unamuno's Poetics”. Comparative Critical Studies 7.1: 41-65

---.2011. “William Blake's Legacy in Miguel de Unamuno's Mature Poetry and Poetics". Estudios Ingleses de la Universidad Complutense 19, 89-104

GIBSon, Ian. 2007. "Antonio Machado, "profesor de lenguas vivas"”. Hermeneus. Revista de Traducción e Interpretación, 9: 1-10

GonzÁLEz, Ángel. 1999. Antonio Machado. Madrid: Alfaguara

Gullón, Ricardo. 1971. Direcciones del Modernismo. Madrid: Gredos, 1971, 1990

Gutierrez-Girardot, Rafael. 1969. Poesía y prosa en Antonio Machado. Madrid: Ediciones Guadarrama

Harvey, Sally. 1990. "La presencia de Wordsworth en la poesía de Antonio Machado" en Antonio Machado hoy: Actas del congreso internacional conmemorativo del cincuentenario de la muerte de Antonio Machado. V. III. Sevilla: Alfar, 45-66

LuCAs, Ana. 1989. “Antonio Machado: la eternidad evanescente del tiempo recordado: estética y temporalidad" en Antonio Machado y la Filosofía. Madrid: Orígenes, 1989, 25-64

Machado, Antonio.1991. Poesías Completas. Madrid: Espasa Calpe

---. 1988. Prosas completas. Ed. Oreste Macrí. Madrid. Espasa Calpe

MANENT, Marià. 1945. La poesía inglesa: Románticos y Victorianos, Barcelona: Lauro

Perojo Arronte, María Eugenia. 2007. “A Path for Literary Change: The Reception of Coleridge's Poetry and Poetics in Spain in the Twentieth Century". Elinor Shaffer, ed. The Reception of Coleridge in Europe. London: Continuum, 167-196

RiBbans, Geoffrey. 2006. “Antonio Machado: de los 'paisajes del alma' al 'alma de paisaje”. Hoy es siempre todavía. Curso internacional sobre Antonio Machado. Ed. Jordi Doménech. Sevilla: Renacimiento, 139-172

SILVER, Philip W. 1996. Ruina y restitución. Reinterpretación del Romanticismo en España. Madrid: Cátedra.

Unamuno, Miguel de. 1966. Obras Completas. Madrid: Escelicer

Wordsworth, William. 1977. Poems, ed. By John O. Hayden, 2 vols. London: Penguin 
---. y Coleridge, S. T. 1998. Lyrical Ballads. Brett, R.L and Jones, A.R. eds. London: Routledge

Wilson, Douglas B. 1993. The Romantic Dream: Wordsworth and the Poetics of the Unconscious. Lincoln, University of Nebraska Press

YNDURAIN, Domingo. 1975. Ideas recurrentes en Antonio Machado. Madrid: Ediciones Turner 